Portland State University

PDXScholar

6-16-2021

\title{
Preparing to Perform: Brillance, by Ida Gotkovsky
}

Connor Fast

Portland State University

Follow this and additional works at: https://pdxscholar.library.pdx.edu/honorstheses

Part of the Music Performance Commons, and the Music Practice Commons Let us know how access to this document benefits you.

\section{Recommended Citation}

Fast, Connor, "Preparing to Perform: Brillance, by Ida Gotkovsky" (2021). University Honors Theses. Paper 1095.

https://doi.org/10.15760/honors.1122

This Thesis is brought to you for free and open access. It has been accepted for inclusion in University Honors Theses by an authorized administrator of PDXScholar. Please contact us if we can make this document more accessible: pdxscholar@pdx.edu. 


\title{
Preparing to Perform:
}

\section{Brillance, by Ida Gotkovsky}

\author{
by \\ Connor Fast
}

An undergraduate honors thesis submitted in partial fulfillment of the requirements for the degree of

Bachelors of Music

in

University Honors

and

Music Performance

Thesis Adviser

Dr. Sydney Carlson

Portland State University 


\section{Table of Contents}

1. Introduction 3

1.1. Preparing a piece of Music 3

1.2. Ida Gotkovsky's Brillance 4

\section{Practice 6}

2.1. Understanding 6

2.1.1. Understanding Déclamé 6

2.1.2. Understanding Désinvolte 10

2.1.3. Understanding Dolcissimo 15

2.1.4. Understanding Final 18

2.2. Interpreting 23

2.2.1. Interpreting Déclamé 25

2.2.2. Interpreting Désinvolte 26

2.2.3. Interpreting Dolcissimo 27

2.2.4. Interpreting Final 29

2.3. Technique 29

2.3.1. The Technique of Déclamé 30

2.3.2. The Technique of Désinvolte 32

2.3.3. The Technique of Dolcissimo 34

2.3.4. The Technique of Final 35

\section{Rehearse 39}

3.1. Piano Tracks 39

3.2. Solo Rehearsing 40

\section{Perform 42}

\section{Bibliography 44}




\section{Introduction}

\section{Preparing a piece of Music}

From pulling sheet music out of the mailbox to standing on a stage, preparing a piece of music for performance takes a lot of work. Oftentimes the audience is not privy to the many hours of practice and study that supersedes a performance of classical music. This thesis serves as a breakdown of the kind of work and practice a musician may undertake to bring a piece to the stage.

Preparation can be broken down into two main stages, practice and rehearsal. While these two things are seemingly similar, and may even be synonymous to a layman, they could not be more separate to a performer. Practice is when the music is learned and rehearsal is when the music is all tied together. ${ }^{1}$ In the case of a solosist, the bulk of preparation time will be dedicated to individual practice.

Once a piece is learned it has to be further developed in rehearsal with the accompanying part, usually either piano or orchestra. With rehearsals completed, the musician can now take their hard work to the stage and share it with the world.

To highlight the work and the steps that it takes to prepare a piece of music I have chosen a solo work off of my senior recital program and tracked my progress of preparation. The piece I have chosen is Brillance, by Ida Gotkovsky.

The practice stage encompassed the majority of work done, with tens of hours of dedicated practice time logged. The practice section of the essay breaks practice down into three essential parts, understanding, interpreting, and technique. In brief,

1 Spaeth Merrie, Practicicing vs. Rehearsing a Presentation: whats the difference and why should you care? Forbes, 2020. 
understanding the music tackles score study and is primarily analytic. Interpreting is done mostly on a trial and error basis for deciding how I want to play the music. Finally the technique part of practice is the applied use of skills and tools to actually learn the music.

The rehearsal stage took a lot less time, with a little less than 10 hours of rehearsal. My efforts were mostly focused on getting familiar with the piano recordings. Finally, my performance of Brillance takes less than 11 minutes.

There are two important things of note about my preparation of Brillance. First is that it was not undertaken alone. My private instructor, Dr. Sean Fredenburg, served as a second set of ears for every step along the way. He transferred onto me the necessary skills and tools that were instrumental in getting this piece together and keeping me on track. Second, all preparation, and the performance itself, was done remotely in accordance with the CDC's COVID-19 guidelines.

\section{Ida Gotkovsky’s Brillance}

Ida Gotkovsky is a prolific French composer with a career spanning over sixty years. Throughout her years composing, she has written ballets and operas, music for orchestras and bands, songs for choirs and vocalists, as well as most abundantly, concerti and chamber music. Of her catalogue is the exemplary piece Brilliance for alto saxophone and piano (1974). A work commissioned by the Royal Conservatory of Brussels. ${ }^{2}$ In this section I will briefly look at the life of Ida Gotkovsky and examine why Brillance is an excellent piece to prepare.

2 Gotkovsky, Ida, chamber workls catalogue, 2017. 
Ida Gotkovsky grew up in a musical family, from which her father was a Russian immigrant. Both of her parents and sister were violinists, however Ida and her brother played piano. Ida Gotkovsky started composing very young, at the age of eight. She would later go on to study at the Conservatoire National Supérieur de Musique et de Danse de Paris (CNSMDP). In her years of formal training, she would study with both Nadia Boulanger and Olivier Messiaen. Both of which have reputations as being some of the best music educators in the history of formal music training. ${ }^{3}$ Messiaen especially influenced Gotkovsky and her body of work as a whole.

Currently, Gotkovsky is a professor of music theory at her alma mater, CNSMDP, though she briefly taught at a University in Texas. In her time as an active composer, most of her works were commissioned by institutions and by state and forign governments. She did write fairly extensively for saxophone as both a solo and chamber instrument.

The question becomes, why did I choose Brillance as my focus? Brillance was an excellent choice for this thesis as it ecompasses many skills that l've been working on in recent years. It is also an appropriate difficulty for my level of musicianship. I knew starting out that it would take a fair amount of work to get this piece prepared enough to perform, and would deliver a good challenge.

3 Surman, Patricia, Gotkovsky, Ida, Grove Music Online, Oxford University, 2020 


\section{Practice:}

\section{Understanding}

To prepare a piece of music effectively, it is imperative to understand the music being played. This is why musicians study music theory, harmony, and form. A convincing performance is more than just playing the notes on the page, it's knowing what those notes mean and how they interact with the music around them. In this section of the thesis, I will delve into the theory of Brillance.

Brillance uses numerous 20th century compositional techniques and nonfunctional harmony, because of this, a traditional harmonic-analysis won't always be relevant or helpful. My analytic efforts will be focused on more than just specific notes but will put a lot of weight on texture, character, and motives. This analysis is my own but is well informed by research and the help of my professors.

As a disclaimer, I can only begin to imagine the intentions of Ida Gotkovsky's composition. This is an analysis made purely to suit my needs as a performer to better understand the music and guide my practice.

\section{Understanding Déclamé}

Déclamé is the first movement of Brillance. Harmonically, Déclamé is the most complex. From the very first chord struck in the piano, it relies on quartal and cluster harmony. In his book, Twentieth-Century Harmony, Vincent Persichetti writes: 
Chords by perfect fourth are ambiguous in that, like all chords built by equidistant intervals, any member can function as the root. The indifference of this rootless harmony to tonality places the burden of key verification upon the voice with the most active melodic line. ${ }^{4}$

The opening chord pictured in figure 1 is an Eb-A-D chord, joined by a $\mathrm{C}$ and a $\mathrm{B}$ in the piano treble clef and saxophone part, respectively. These notes could be

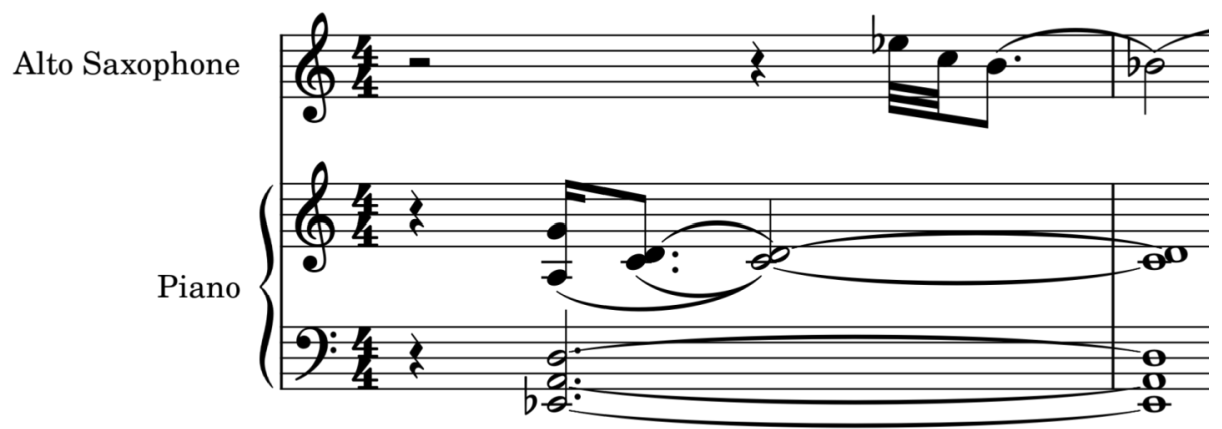

Figure 1: Brillance, Déclamé $m m$. 1-2

rearranged to spell out a B-Eb-A-D-G-C six note quartal chord, where the $G$ is played only briefly and the rest are held. This type of extended quartal harmony continues throughout the first half of this movement, where a three-note quartal chord is played in the piano bass clef, and an accompanying two notes a step apart is played in the treble clef, a good example is pictured in figure 2 .

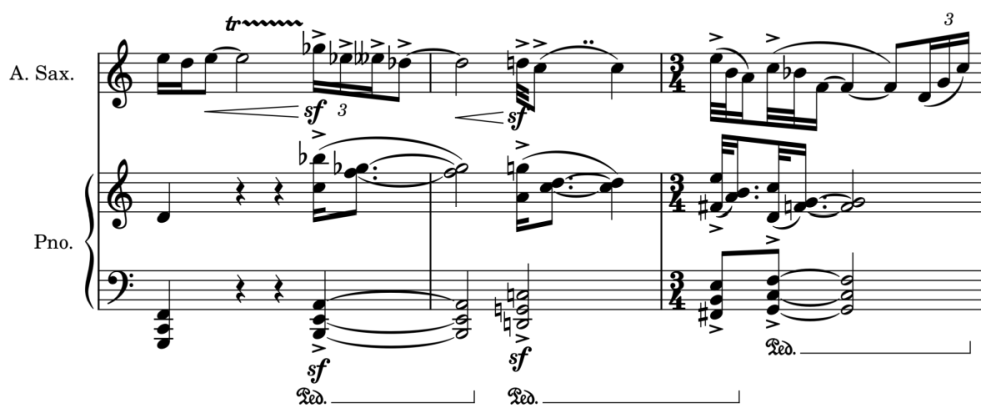

Figure 2: Billance, Déclamé rehearsal $A, m m .1-3$

4 Persichetti, Vincent, Twentieth Century Harmony, Creative aspects and practice, W.W. Norton \& Company, $4^{\text {th }}$ edition, 1961. 
Starting at rehearsal letter B there is a notable texture and character change. In $5 / 4$ time, the rhythm in the saxophone part becomes noticeably more metric. That being said, Gotkovsky writes an eighth-note triplet figure tied over the beat, seen in figure 3 . This rhythm has an off-kilter feel, especially when juxtaposed by the 16th notes. Harmonically, this section is supported by octaves in the piano. Tonally, this harmony is hallower yet there is less ambiguity.

A. Sax.

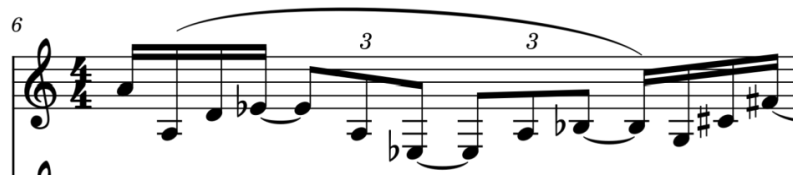

Figure 3: Brillance, Déclamé rehearsal B, m. 2

At rehearsal $\mathrm{C}$ the character and texture shift back, similar to the first half, however both the harmony and melody are a bit more active. From this point on, quartal harmony is abandoned for cluster chords (tone cluster), pictured in figure 4. If quartal harmony is mildly tonally ambiguous, wherein a root is established by the melody, then a tone cluster takes this a step more. Roots aren't really established, instead the chords function more as white noise. Where every note played in the melody will form both dissonances and consonants with different pitches at the same time. 


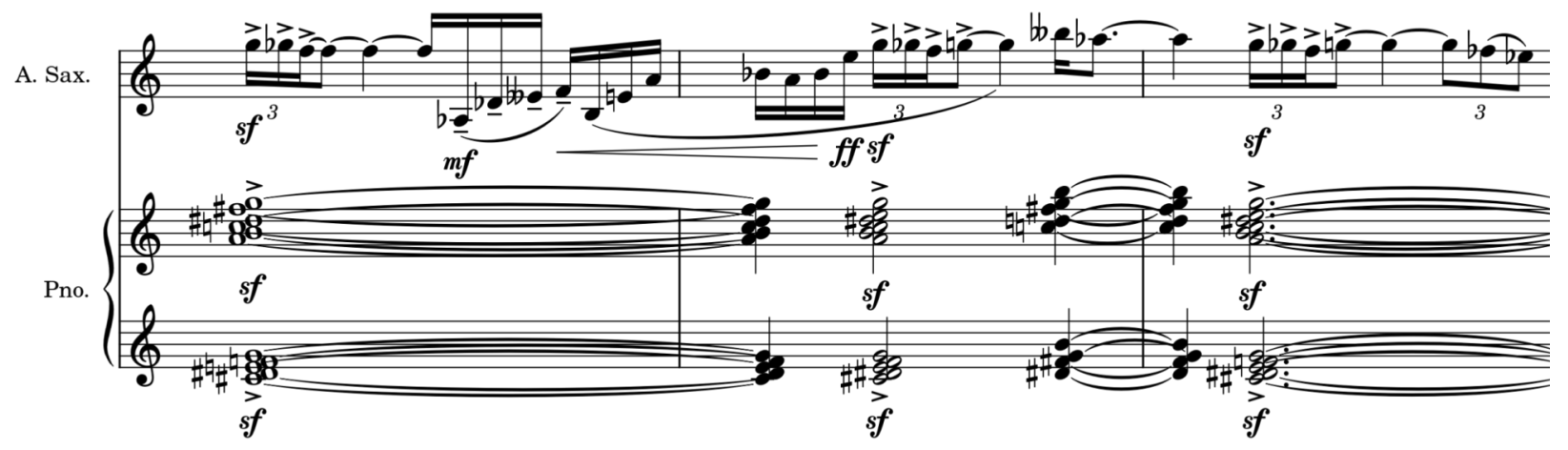

Figure 4: Brillance, Déclamé rehearsal C

Tone cluster harmony is used through to the end of this movement. There is a discrepancy at the very end. The final and penultimate measures have a prominent $C$ pedal point ringing under the extended chord. At this point, the saxophone is playing a concert A. This is actually the only note letter from the musical alphabet missing in the piano part. With B through G present in multiple octaves with C-sharp, F-sharp, and Eflat.

Stepping back from harmony, Déclamé does quite a lot with its use of motives. Referring back to figure 1 , The most prominent motive is stated in the saxophone part. It's stated multiple times in both the saxophone and piano parts, stated with both rhythmic augmentation and diminution. It can be seen in the saxophone part of figure 2,4 , and 5 . My favorite example of this motive is in figure 5, which features a severely augmented version in the saxophone and various states of augmentation in the piano part. 


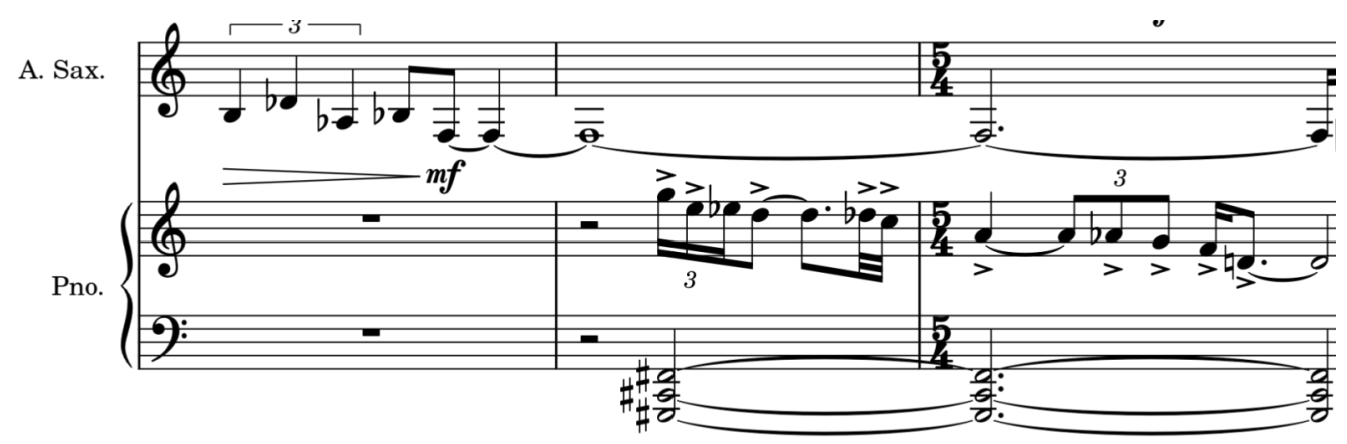

Figure 5: Brillance, Déclamé mm. 4-6

\section{Understanding Désinvolte}

Désinvolte is the second movement of Brillance, and the first technical movement of the piece. Where Déclamé relies on more open ambiguous harmony, Désinvolte uses an abundance of chromaticism.

It opens with an A diminished triad in the piano and the saxophone is running down thirds. These thirds have some chromatic steps in them, but they do hint at the key center of B-flat natural minor, pictured in the first two measures of figure 6 . The key center is further enforced by hovering around the note B-flat, with the chord in the bass serving as the vii ${ }^{\circ}$ chord in the key of B-flat, seen in figure 6 in the second two measures. 


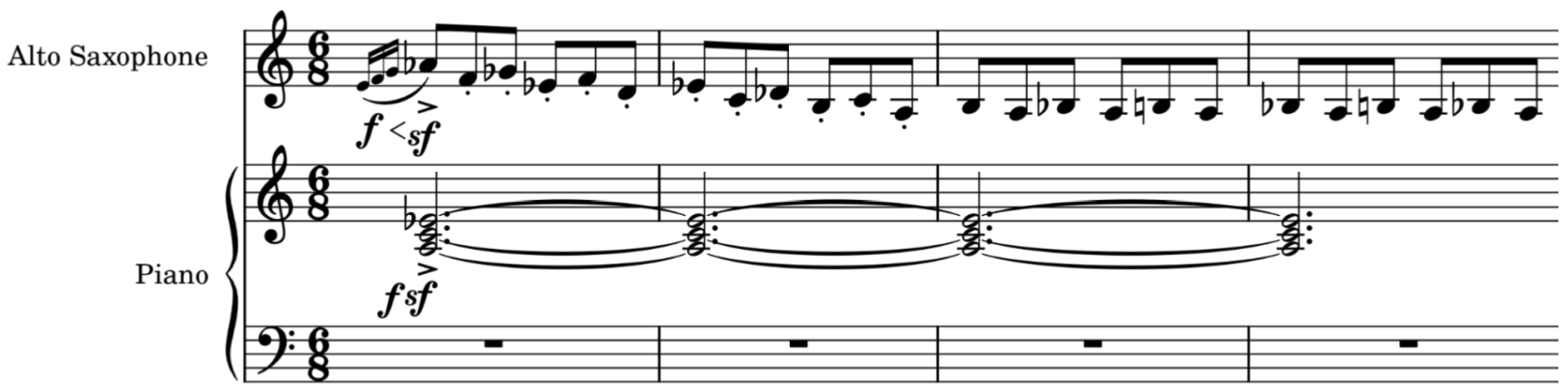

Figure 6: Brillance, Désinvolte mm. 1-4

However this key center is quickly shifted away from. With a D-Sharp diminished triad in the bass. The saxophone doesn't hint at a key center as clearly, and could be interpreted as any number of tonalities. This section is better described as an overall descending line using chromatic thirds. At this point the piano joins the saxophone's rhythm, with straight 8th notes. This homorhythmic texture is much more angular.

A. Sax.

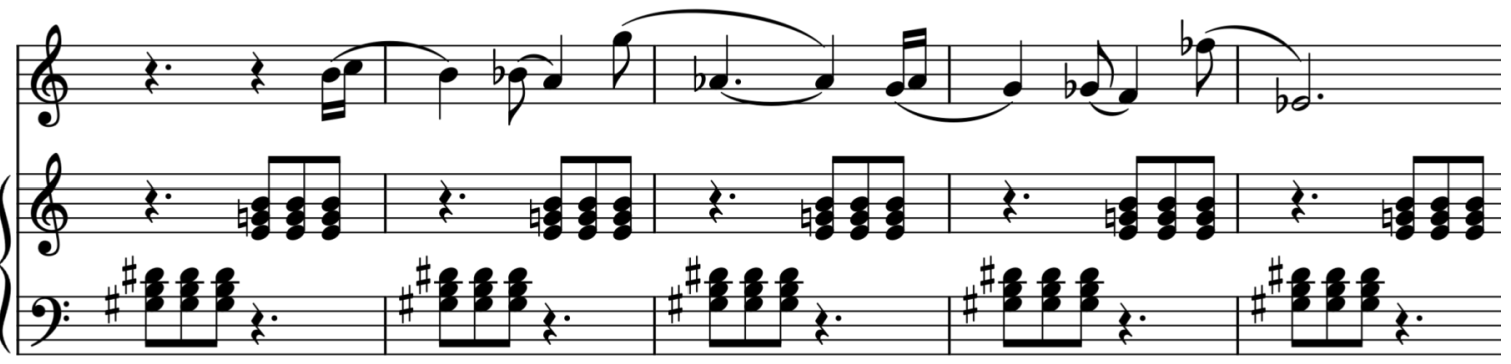

Figure 7: Brillance, Désinvolte rehearsal B, mm. 2-6

In the third measure after rehearsal $\mathrm{B}$, new material is introduced, refer to figure

7. This is an overall descending chromatic line, with some embellishing. It is supported by $\mathrm{E}$ minor and G-sharp minor triads in the piano part; these chords have a chromatic 
third relationship to each other. It is by far the most melodic line in this movement. It occurs a couple of times and is the only part of this movement that is actually themelike.

Following this more melodic line the parts go into a hemiola, pictured in figure 8 . This hemiola is an off center duple feel within the compound meter. The time change to $4 / 8$ in this section is inconsequential as it only serves to land the line on a downbeat.

A. Sax.

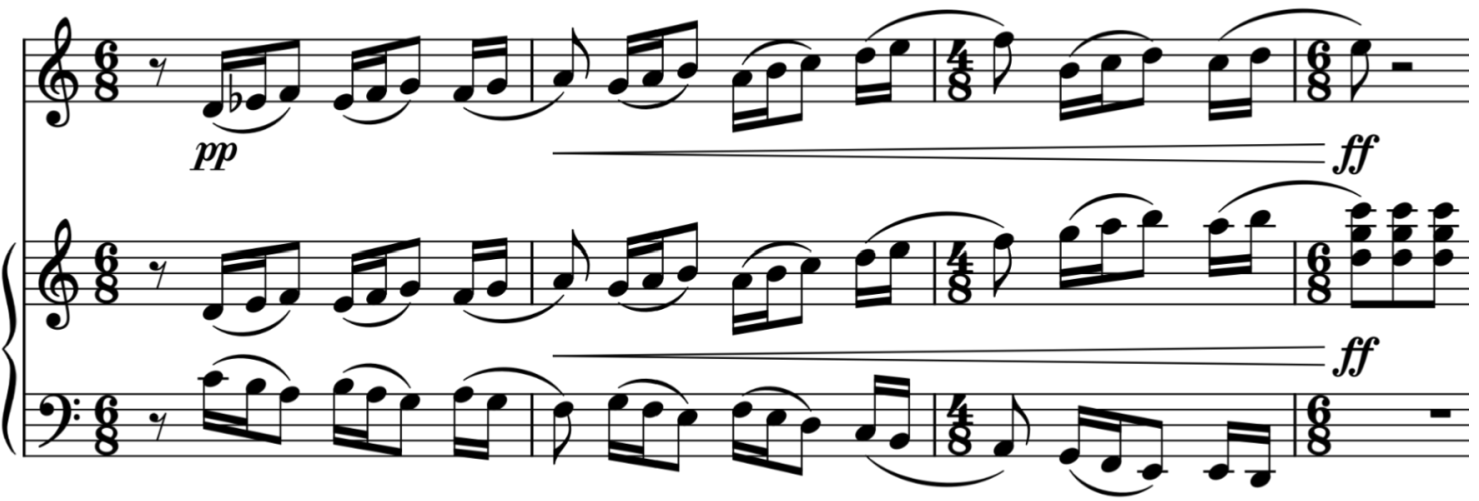

Figure 8: Brillance, Désinvolte rehearsal B, $\mathrm{mm}$. 7-10

The next section of this piece is similar to the beginning, though it features more ascending third figures. The first use of $5 / 8$ time appears and is accompanied by a sequence, see figure 9 . This is the first consequential time change in the movement that reflects something different. It carries into another descending chromatic melody, 
followed by the same hemiola figure.

A. Sax.

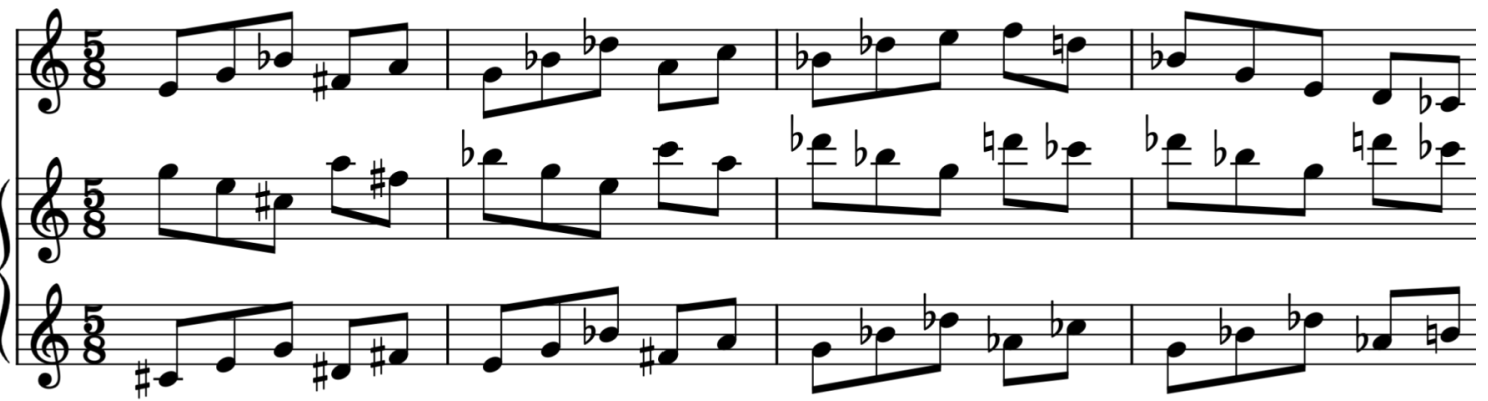

Figure 9: Brillance, Désinvolte rehearsal C, 9-12

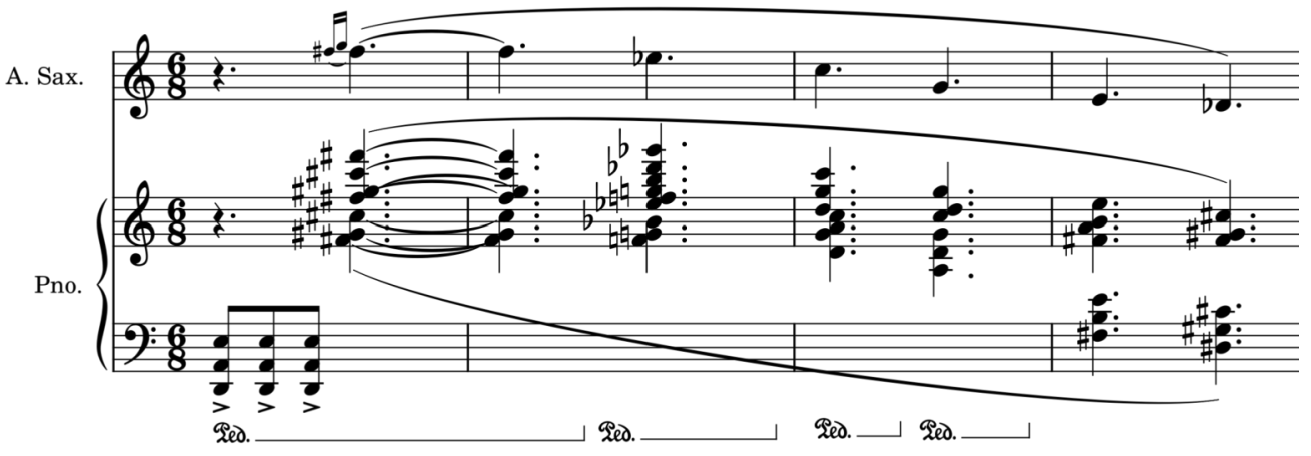

Figure 10: Brillance, Désinvolte rehearsal F, mm. 9-12

The final stretch of the movement includes more straight eighth notes occasionally hinting at some key centers. Although, very suddenly, there is a quick change in texture and character completely right before rehearsal G. The saxophone holds long notes, relative to what had been played, and is supported by open 
quartal/quintal chords in the piano, see figure 10. It does this same line again, a little bit more elongated and a little bit higher in pitch. The music denouements into material very similar to the beginning. Just as the melody hovered around B-flat, in figure 6 , this new material hovers around F-sharp. There is a gradual rise out of this, in both dynamic and pitch, cultivating in an explosive measure of grace notes into rising pitches, see figure 11. This aggressive measure is reinforced by tone clusters planed by thirds in the piano. This is the climax of the movement.

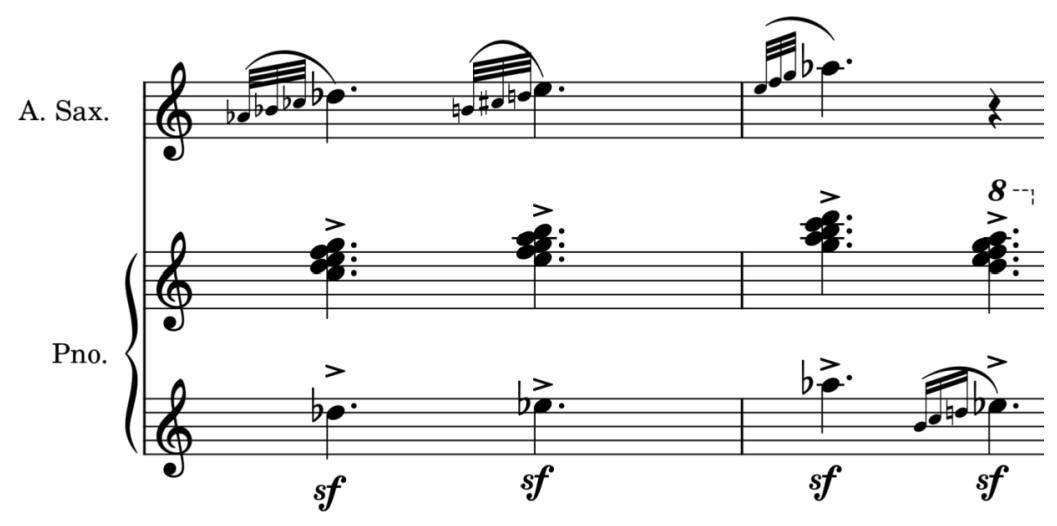

Figure 11: Brillance, Désinvolte rehearsal G, mm. 14-15

After the aggressive climax, harmony in the piano part returns to quartal and quintal chords. As the piano plays that harmony, the saxophone part sets up on its high E for nine straight measures, with only brief grace notes interlaced. This could be serving as a pseudo pedal point. After some similar material and a long diminuendo the movement ends with all parts on an $\mathrm{E}$.

In a formal analysis, l've settled on this movement being a loose binary form. Formal analysis of contemporary music can be largely unfruitful because the "rules" of form are often ignored in later compositions. ${ }^{5}$ That being said, there are trends in this 
movement that hint at a broader structure.

From the very beginning to through the hemiola, up to rehearsal $\mathrm{C}$, is the first section (A). From rehearsal $C$ up though the next hemiola and to rehearsal $F$ is the next section $\left(A^{\prime}\right)$. Both of the sections, while not exactly the same, both start with straight eighth notes, have the descending chromatic melody, and effectively end with the same hemiola, see figure 12 for the road map of the A sections. The next section is rehearsal $F$ to the end of the movement. This section (B) holds a lot of new material as well as what I've found to be the climax of the piece.
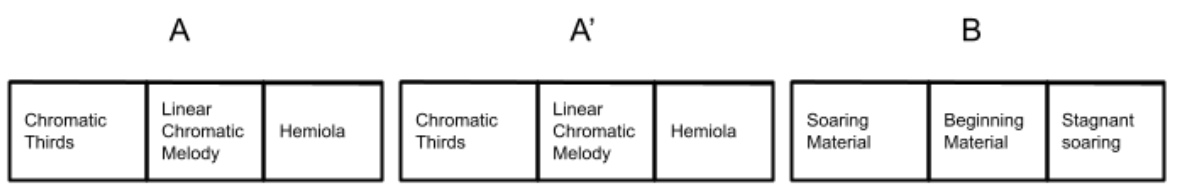

Figure 12: Brillance, Désinvolte road map

The effective form of this piece is $A A B$ form. To be a true binary form the $B$ section would have to be repeated as the $A$ was, so it is a loose interpretation. The $A A B$ form is sometimes called "bar form." However bar form was much more common in German music and isn't a universally taught form. All of Gotkovsky's teachers were French so it's unclear if this is a form she would have been thinking about while composing.

\section{Understanding Dolcissimo}

Dolcissimo starts with a repetitive 16th note harmony in the piano part. Like the 
other movements mentioned so far, this harmony relies heavily on fourths and fifths. The accompanying part may have some slight variations, however for the most part it plays these three chords: Eb-Ab-Db, Fb-Bb-Eb, and Db-Ab-Fb-Eb. See figure 13 for a visual of the accompanying part.

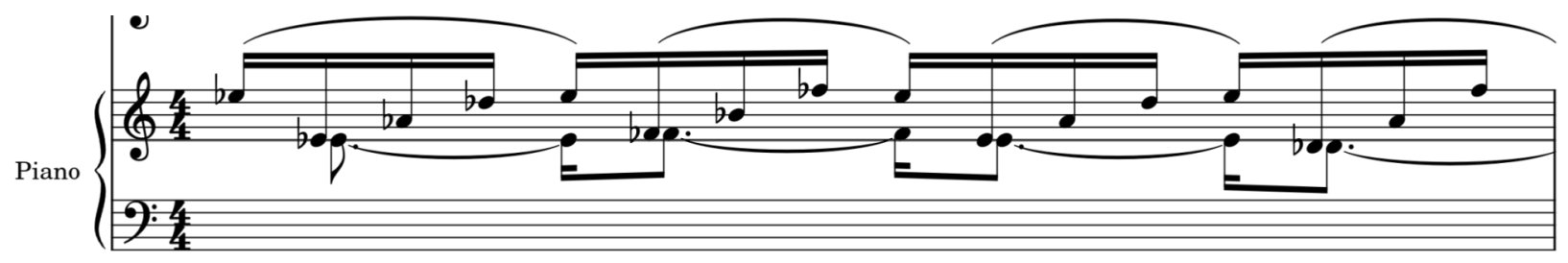

Figure 13: Brillance, Dolcissimo m. 1

As for the melody, Dolcissimo has a very soft delicate melody played by the saxophone. This movement makes use of elided phrases, as endings bleed into begins. See figure 14 as an example of elision. As that $A b$ is finishing its resolution it is cut short by the sudden start of the next phrase. It's an effect brought about by the missing 16th note in the measure.

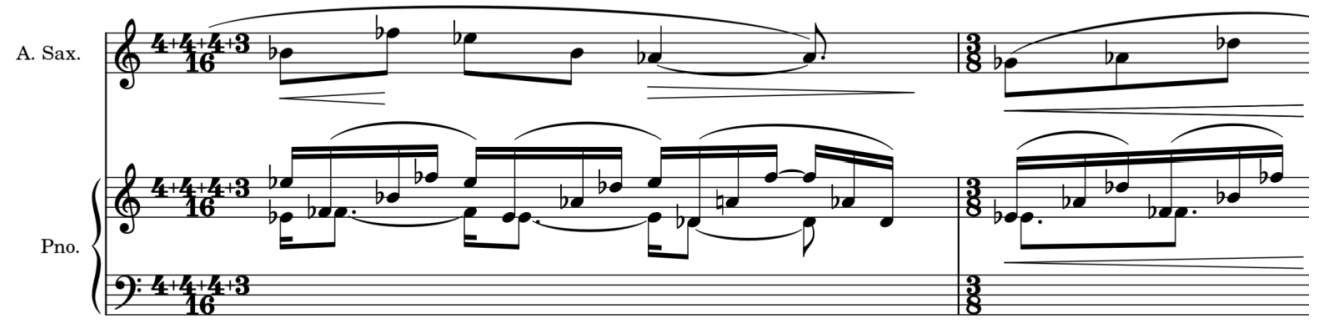

Figure 14: Brillance, Dolcissimo mm. 3-4

There is a change of pace and character at rehearsal A. The piano is underscored by low octaves and tighter harmony in the bass clef. The saxophone part moves on from the winding melody to a more stationary firm one, see figure 15. 


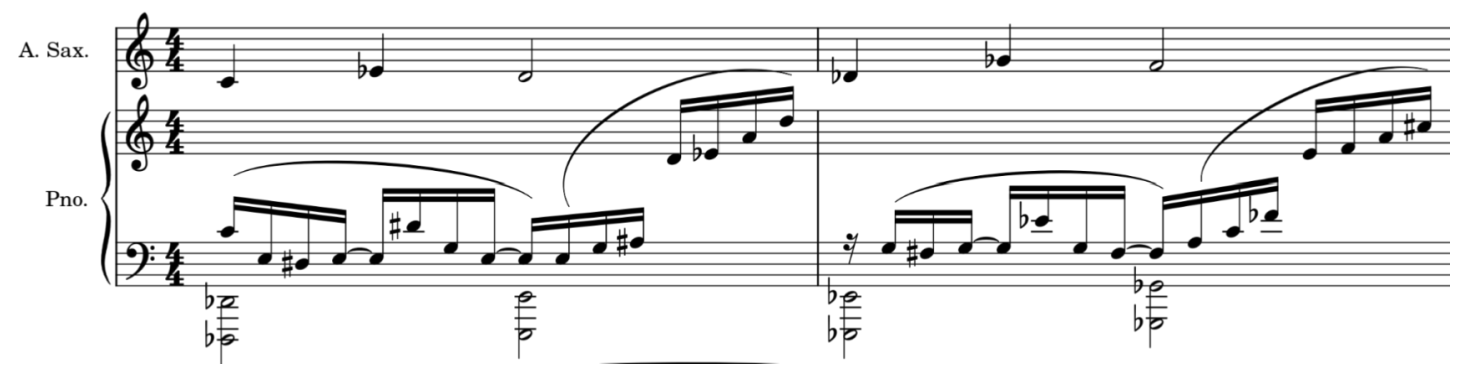

Figure 15: Brillance, Dolcissimo rehearsal A

The parts have a simultaneous slow growth in dynamics and miniscule growth in tempo until rehearsal $\mathrm{B}$.

Rehearsal B still has the same low octaves in the piano, however the saxophone has a crescendo and plays a line into a long held F-sharp. During this hold the piano has a short line spanning four and a half octaves which hands off to the saxophone part. The saxophone takes the handoff and runs the line back down and up again, see figure 16. This interplay between the piano and saxophone continues for a short while until a denouement is reached at rehearsal C.

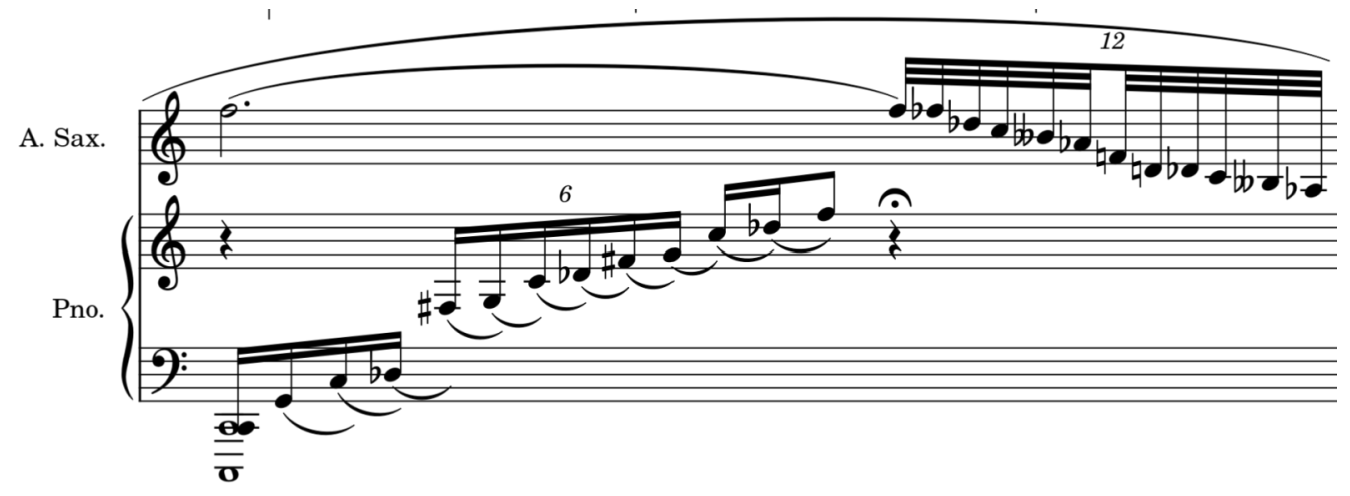

Figure 16: Brillance, Dolcissimo rehearsal B, m. 2

This section at Rehersal C sees a return of quartal harmony. However, instead of the 16th note pattern as before, this harmony harkens back to earlier movements with 
open block chords of fourths. The melody at this time has a couple of short runs in the D-flat phrygian mode. The modal section is short lived as it swiftly chromatically modulates to some mode of E-flat. After this modulation, the music returns to material from the very beginning of the movement, however the parts have now switched roles, see figure 17 . This only lasts one phrase as the saxophone retakes the melody at rehearsal E. Both piano and saxophone play similar parts from the beginning to the conclusion of the movement.

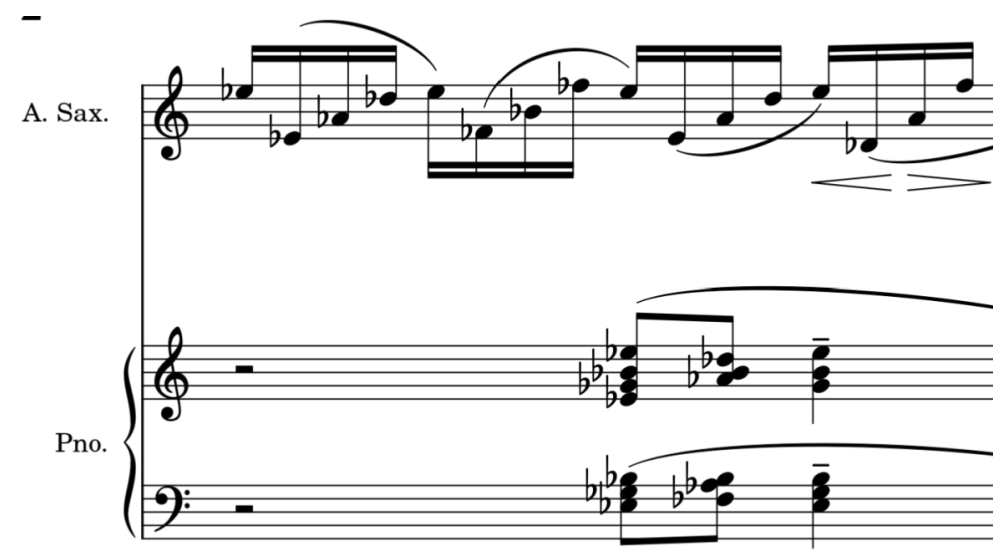

Figure 17: Brillance, Dolcissimo rehearsal D

\section{Understanding Final}

Final is the last and most technical movement of Brillance. There are a lot of notes to be played and so an in depth analysis wasn't necessarily as important. A thorough analysis would have required parsing through the countless non-harmonic tones and counterpoint which could have inevitably bogged down my practice on the technique front. Instead, this analysis will focus on the broader trends within the music that are still relevant to a performer's understanding. 
To begin, Final starts by setting up a dichotomy between major and minor chords, see figure 18. This opening shows the quick modal change of the $G$ triad before moving into a run up a B-flat aug maj 7 chord, seen in figure 19. This winds down in a mostly scaler fashion into rehearsal $A$.

Alto Saxophone

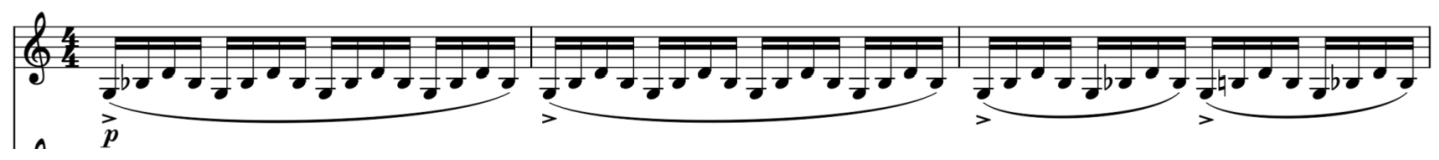

Figure 18: Brillance, Final mm. 1-3

A. Sax.

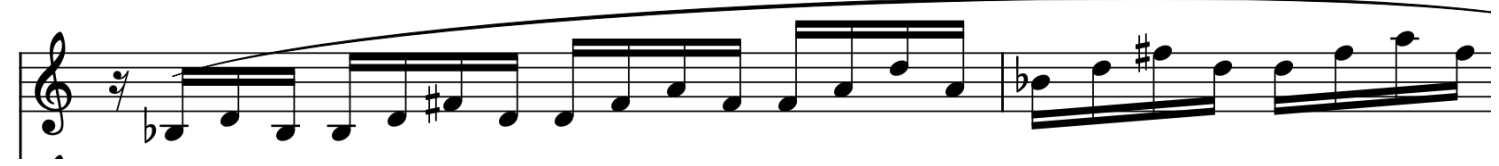

Figure 19: Brillance, Final mm. 4-5

At rehearsal A, the piano part starts playing the same pattern the saxophone started with, except this time the dichotomy is between E minor and E diminished. The saxophone comes back in at rehearsal B playing a line similar to the augmented one mentioned earlier, though this time it is primarily focused around diminished chords, see figure 20. 
A. Sax.

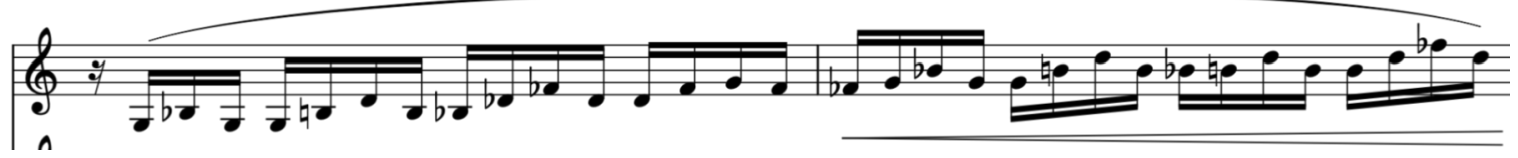

Figure 20: Brillance, Final rehearsal B

The saxophone part from here to rehearsal $\mathrm{C}$ mostly just moves around various chords including Eb minor, D minor, C minor, and D-flat augmented. Harmony in the piano up to rehearsal B was fairly limited, however from rehearsal B to rehearsal C the piano part supports these chord changes with octaves. For the most part the harmonic rhythm is a new chord per bar. See figure 21 for a visual of the piano harmony against the measure in $D$ minor.

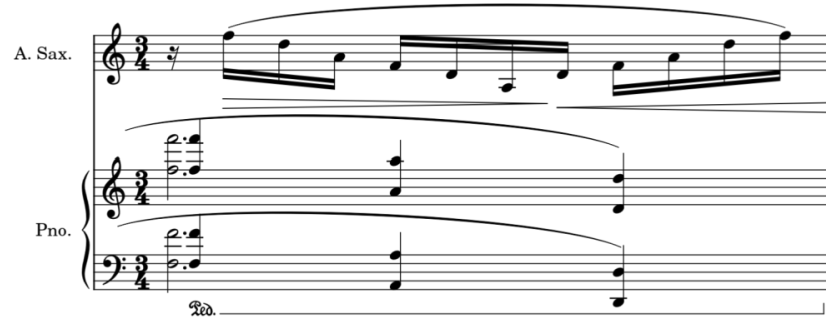

Figure 21: Brillance, Final rehearsal B, m. 4

At rehearsal $\mathrm{C}$ the saxophone part moves to a repetitive line hovering around the note $\mathrm{C}$ where piano is now most implicative of harmony. This piano harmony includes extended chords where a loose functionality could be guessed at, but for the most part remains nonfunctional. Following this part the saxophone enters into a pseudo cadenza composed primarily of chromatic movement.

What follows, through rehearsals $E, F$, and $G$, is a highly rhythmic asymmetrically metered section. With little discernible pattern, the music rapidly shifts between $7 / 8,3 / 8$, 
and $9 / 8$ time. The $7 / 8$ stress pattern is consistently $3+2+2$ except for one measure of $2+3+2.9 / 8$ measures are always stressed as $3+2+2+2$. The piano supports these time changes with mostly triadic harmony in the treble clef and various chords and clusters in the bass clef, see figure 22 .

A. Sax.
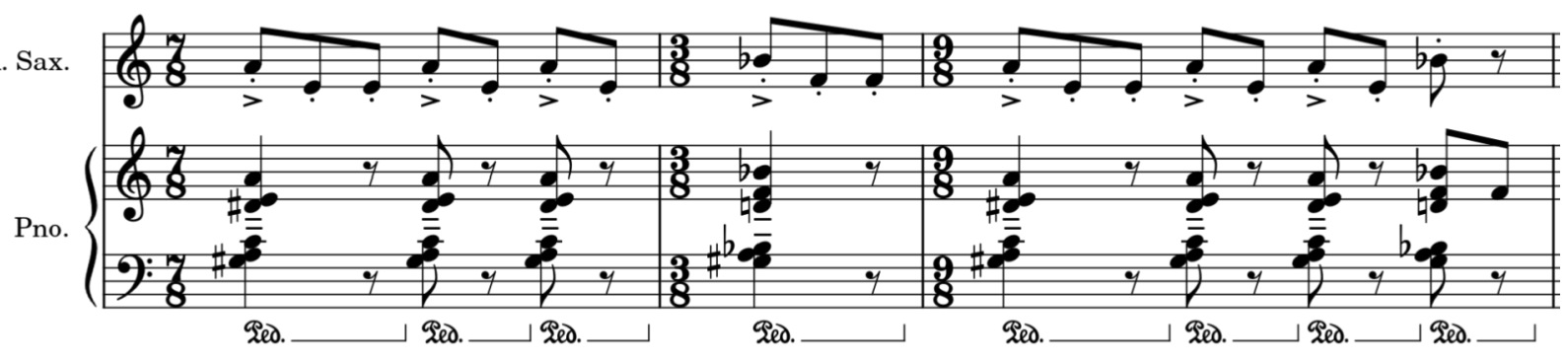

Figure 22: Brillance, Final rehearsal $F$

Rehearsal $\mathrm{H}$ consists of straight 8th notes in the piano and a fair amount of chromatic movement and compound leaps in the saxophone. This is a short section, mildly transitional to rehearsal I.

Rehearsal I has a change in texture as the piano plays block chords, and the saxophone flourishes. The first flourish the saxophone has is an Eb augmented maj 7 chord. The second is on the same chord but with the added F-sharp, see figure 23. What follows is the saxophone running up and down a B-flat augmented maj 7 chord, 
against the piano which is playing $\mathrm{G}$ maj 7 chords with a split third, see figure 24 .

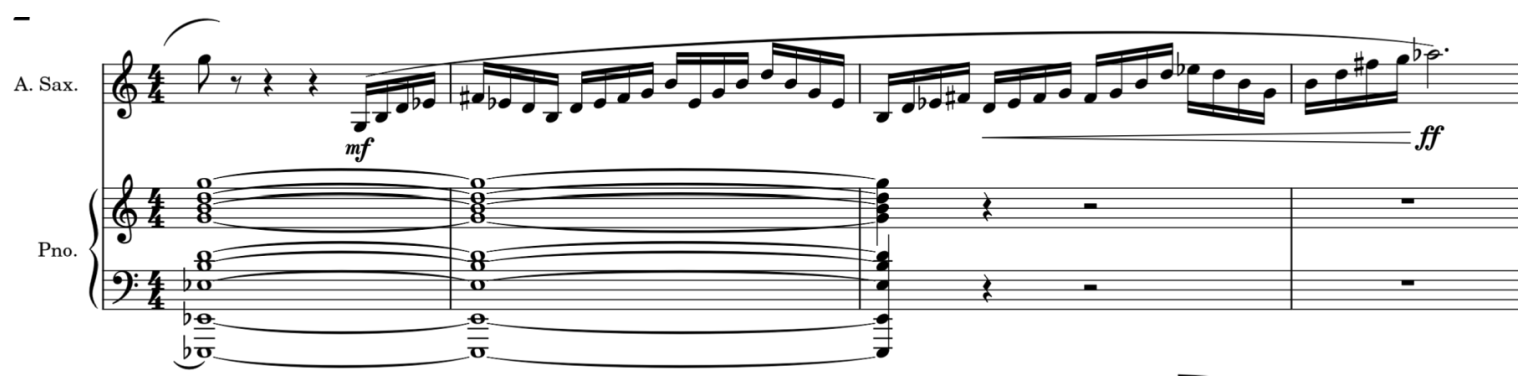

Figure 23: Billance, Final rehearsal I, mm. 4-7

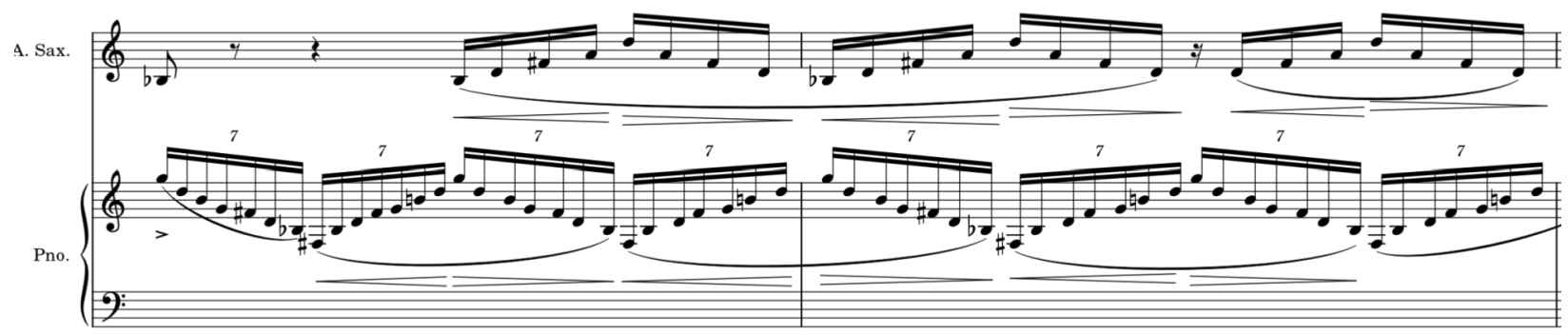

Figure 24: Brillance, Final Rehearsal J, mm. 1-2

Material from the beginning comes back at rehearsal $\mathrm{K}$, with the same type of major/minor dichotomy, this time on E-flat minor and E-flat major. This material actually gets developed this time around and goes through some alterations leading up to rehearsal L. Rehearsal L has great interplay between the saxophone and piano parts, but similar to rehearsal $\mathrm{H}$, it serves mostly as transitional material.

The movement ends with a sprint from rehearsal $\mathrm{N}$ to the end. This final section sees the return of quick random time changes, akin to rehearsals E-G. Though this time the changes include $7 / 8$ and $5 / 8$. The $7 / 8$ keeps the same stress pattern as before, $3+2+2$. However the $5 / 8$ is less consistent, featuring both a $2+3$ and $3+2$ pattern. The 
piano part takes up the role the saxophone had been playing at rehearsals $\mathrm{E}-\mathrm{G}$, the straight eighth notes. The saxophone is now playing a 16th note pattern over the time changes. Most of this section is a long slow crescendo gearing up for the finale.

The finale is a loud bombastic outcry from the saxophone. Encompassing quick beats of flourishes and held high notes at triple forte. $\mathrm{C}$ major chords in the bass of the piano serve as a pedal point, while the saxophone plays along with the piano's treble clef harmony, which is an A-flat augmented 7 th chord, see figure 25 . Eventually the saxophone grows tired of belting this counter harmony and settles on a $\mathrm{C}$ to conclude the movement and the piece.

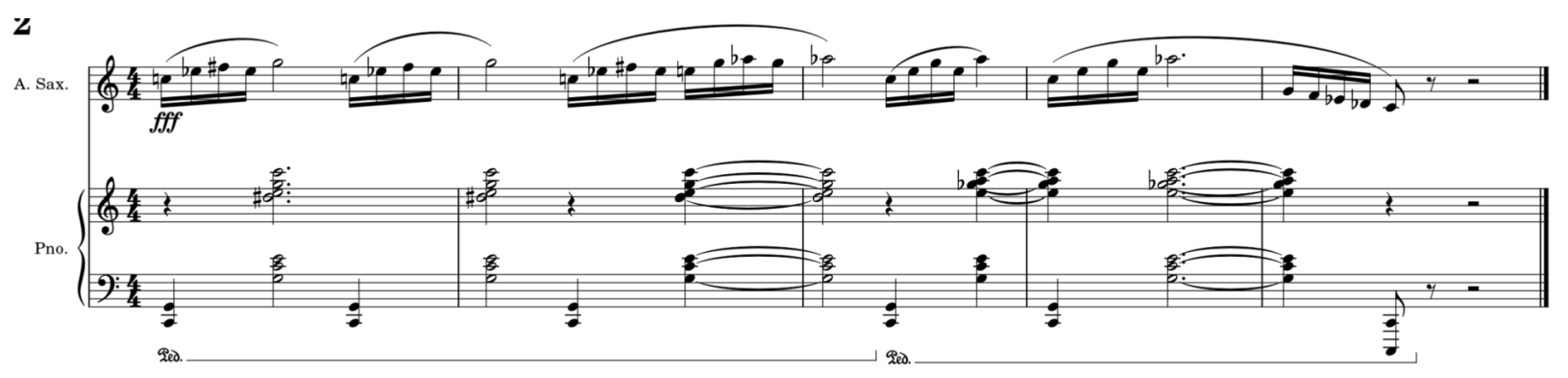

Figure 25: Brillance, Final rehearsal $P, \mathrm{~mm} .7-11$

\section{Interpreting}

A convincing interpretation can separate an armature from a professional. This step in the process of practice can take many forms, from deciding where a breath should be drawn to full movement characterizations. Interpretation is how one plays beyond the ink on the page.

In my process of preparing, interpretations were decided by conscious decision through trial and error. I tried new things when working on movements, and sometimes I 
would like them and sometimes I wouldn't. I listened to numerous recordings such as the ones by the Nascilansy Duo ${ }^{6}$ and William Chien ${ }^{7}$ to determine what I did and didn't like.

Gotkovsky has a musical credo that is important to know in the context of playing her music. She pledges to "create a piece of art which is universal and which, thanks to the use of a strict modern language, helps to create a unity in the musical expression of all times." ${ }^{8}$ With this in mind it was also beneficial to listen to other Gotkovsky saxophone pieces. Her Quatuor de Saxophones, Variations Pathetiques, and Eolienne in particular are great pieces that have a similar atmospheres are characters to Brillance.

Most importantly, I never wanted any choice that I made to go beyond the will of Ida Gotkovsky. No choice that I made directly goes against the sheet music. A philosophy of interpretation and performance was well said by Igor Stravinsky in his poetics:

... no matter how scrupulously a piece of music may be notated, no matter how carefully it may be insured against every possible ambiguity through the indications of tempo, shading, phrasing, accentuation, and so on, it always contains hidden elements that defy definition because verbal dialectic is powerless to define musical dialectic in its totality. The realization of these elements is thus a matter of experience and intuition, in a world, of the talent of the person who is called upon to present the music. ${ }^{9}$

These interpretations have been formed through my own study and practice and are not representative of what is "correct" or "right," they are simply how I choose to play the music.

6 Nascilansk Duo, Brillance Ida Gotkovsky, nascilanks Duo, youtube, 2018.

7 William Chien, Ida Gotkovsky-Brilliance, William Chien, youtube, 2017.

8 Gotkovsky, Ida, Catalogue, 2017.

9 Stravinsky, Igor, Poetics of music, Harvard University Press, 1947. 
Interpreting Déclamé

When determining how Déclamé should be played, look no further than the title.

Déclamé means "declared" in French. Every statement of the motive mentioned in 2.1.1 should be a declaration. It's never meek, always strong and assertive. Ida Gotkovsky said of this movement, "takes place in the style of great lyrical improvisation.." ${ }^{10}$ It should emulate a great operatic recitative.

The music is trying to prove a point, as if in an argument. The motive is often built to, exploding quickly and forcefully out of a sudden crescendo. Culminating in the final statement of the motive happening consecutively on the same pitches in the final measures. As if the final point of the argument has been reached and the belligerent is repeating it for emphasis.

The argument metaphor actually carries even deeper than just motivic declarations. When the movement starts, it's a relatively active solo part with moments of aggression, and it's underlined by the quartal harmony discussed in 2.1.1.. The character change at rehearsal $B$ could be interpreted as a more subdued anger. Like a pot simmering and bubbling. Then at rehearsal $\mathrm{C}$ the solo reaches its loudest point, like the pot boiling over. It's as if the person arguing is trying to calm themselves down but is ultimately unsuccessful. From then on, the harmony dissolves to the tone clusters and the motive is even more prevalent. The eristic is completely unhinged from rehearsal $\mathrm{C}$ on.

When I play this movement I try to internalize and declare this argument through

10 Gotkovsky, Catalogue, 2017. 
the music. The expressive text attached to the first note reads, "Sonorous, Quasi recitative." This recitative style gives me, the performer, the freedom to express each declaration in line with my interpretation.

Interpretation goes beyond just the character the piece calls for. It also informs decisions about phrasing. As a universal rule, I never take a breath between a crescendo and the explosive motive. This piece has long phrase markings, so there weren't many decisions to be made about what the phrases are.

\section{Interpreting Désinvolte}

The crucial step in deciding how to play Désinvolte was to decide how I was going to characterize the movement. This movement defines its character in both its title and its style marking.

Désinvolte means "casual” in English, though I think this movement isn't casual at all. I take this title to have three possible meanings and they could be right simultaneously. One, it's an ironic title. There isn't anything casual about this movement except the chromatic melodious line. It is stress inducing to play and to listen to. Two, it's the follow up to the Déclamé argument. Where Déclamé ended with the final point of an argument, Désinvolte picks up with the two combatants trying to be civil around each other. It represents a grumbling attitude behind a calm and casual facade. Thirdly, it's supposed to seem easy. The audience shouldn't know the difficulty of this movement, to them the performer should be casually collected on stage as they rip through these notes. 
This title could have any number of definitions depending on the performer. In my interpretation, I take it as the first and last possibility listed; as an ironic title for a movement that is far from simple, but has to sound easy. To accept a metaphorical connection to the first movement would imply some sort of metaphorical connection to the others, which I have not found to be true.

Gotkovsky's own program notes say, "Fugitive, humorous, the extremely fast theme alternates with the piano in a bouncy detached pianissimo." ${ }^{11}$ This quickness is marked as "Avec Humour", or "with humor." To play this movement convincingly I would have to play it with humor. To me, that implies a certain bouncy light quality to the playing.

Interpreting Dolcissimo

The interpretation of Dolcissimo actually leaves little to the imagination of the performer. I do find it to be an absolutely stunningly written piece, but there isn't much for the performer to work out in terms of how they'd interpret it. This is actually backed up by Gotkovsky's own notes of the movement, "Linear, this movement of atmosphere where the timbre colors follow one another is very expressive in an extreme softness." ${ }^{12}$ In these notes, she's calling the writing itself colorful and expressive.

Dolcissimo means "very sweetly" in French. This characterization is omnipresent throughout the movement. A title like this as well as the style marking "molto dolce" which also means "very sweet" involks a style of delicate melodiousness. I try to carry

11 Gotkovsky, Catalogue 2017.

12 Ibid. 
this character throughout my performance of the piece.

The general rules that I tried to adhere to in preparing and performing this piece were quite straight forward. Firstly, I was to not breathe between the elided phrases, as it ruins the effect. Secondly, any held long notes I had were to not get in the way of the piano flourish. This means not playing the long notes too interestingly with dramatic dynamic shifts or distractive vibrato. Finally, when the piano and saxophone parts switch rolls, I am to match the style the piano started with. This gives homogeneity to the performance as a whole.

For the most part, the best way that l've found to play this movement is to not get in the way. It is composed very well and can speak for itself without me having to input too much interpretation. The only part of this movement where I do have free reign to interpret is during the ad lib. measures after rehearsal B, shown in figure 26.

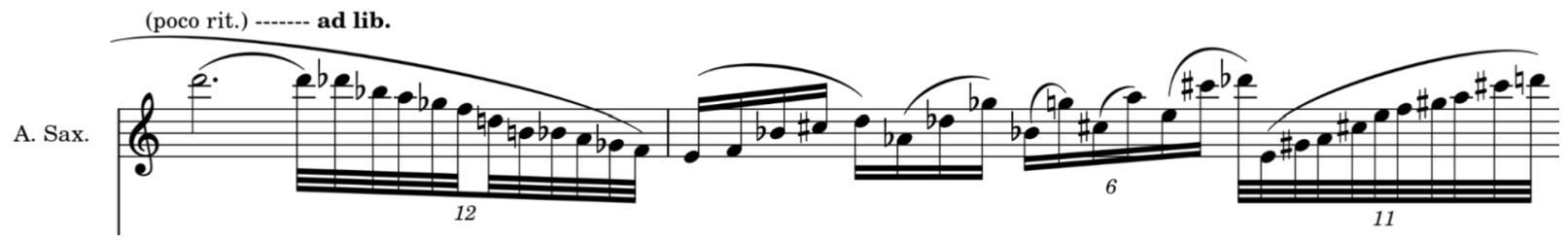

Figure 26: Brillance, Dolcissimo rehearsal $\mathrm{B}, \mathrm{mm} .2-3$

Ideally, my performance of this line wouldn't compromise the rhythmic notation. I settled on having the initial run-down from $D$ to $F$ speed up a little. The following 16 th notes would be played with little variation and the sextuplet would heavily emphasize the two not groupings. I would breathe after the D-flat on the fourth beat and start playing the rest of the tuplet at a moderate speed. The tempo would pull back ever so slightly on the last few notes to emphasize the next downbeat. 


\section{Interpreting Final}

Final has quite a lot going on and the piece is primarily characterized by swift motion. This leaves little need for decision making in interpretation. In Gotkovsky's words, "Virtuosity, rhythm and dynamism dominate this Final. All the difficulties of the Saxophone are present there. After an impetuous dialogue, the work ends with strength and joy." ${ }^{\prime 3}$ The character of this piece is that it is fast, so naturally the best interpretation is playing it accurately. Going about this is covered in the Technique section.

The pseudo cadenza did leave some room for interpretation, though I tried to keep my rhythms and pattern notation accurate. I thought that the solo chromatic movement of this cadenza was really dramatic and I didn't want any sort of interpretation to get in its way.

\section{Technique}

The only way to build strong technique is to put the work into developing it. Learning technique in this context is two faceted. The first part is learning applicable patterns and skills that transfer to the sheet music. The first patterns a young performer might learn are the major scales, and they learn them to develop versatility in those keys. Higher levels of play also require applying learned patterns and skills, they just get more complicated. Secondly, it is as simple as learning sheet music. This is easier said than done.

In this thesis I walk through the specific steps I took to learn certain patterns as

13 Ibid. 
well as the sheet music itself. As a general rule, practice developed slowly and deliberately. Every pattern I learned and line I played was played many times slowly before even approaching performance speed.

\section{The Technique of Déclamé}

Déclamé is not a technical movement. However, certainly things about it need practicing. My first step to preparing this movement technically was playing it with a metronome. The rhythms in this movement are not as straightforward as the others, so playing with the metronome on an eighth-note subdivision was crucial to rhythmic accuracy and development.

Something in particular I focused on practicing was consistency in playing the motive. This motive as mentioned in 2.1.1. and 2.2.1. is ubiquitous throughout the movement. So it was a goal of mine to give it some uniformity throughout its statements. Figure 27 is an example of something I would practice to achieve uniformity. Playing these important motivic declarations consecutively fine tunes them to be similar in practice and performance.
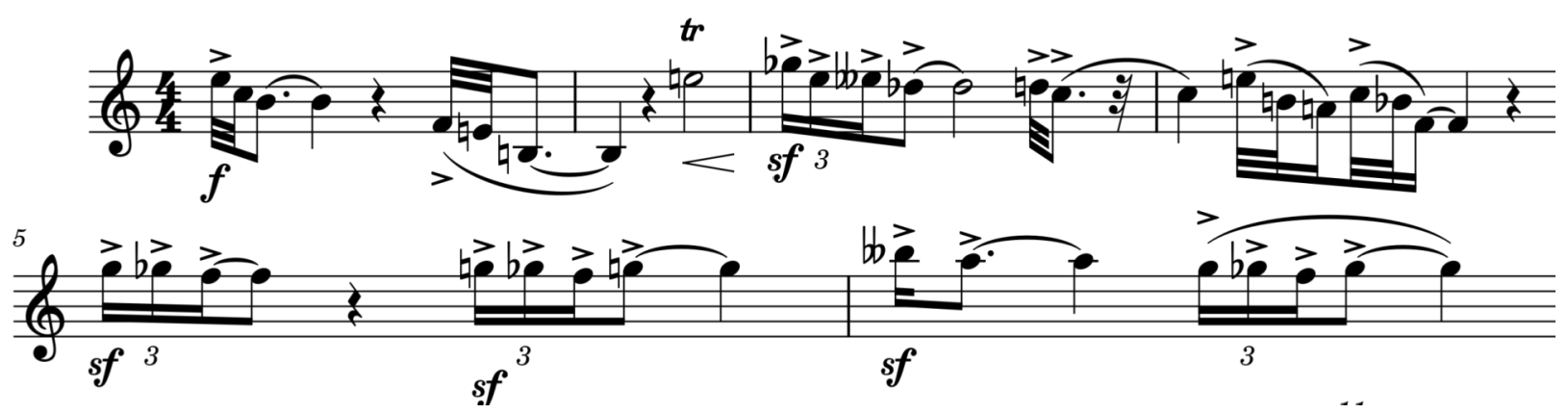

Figure 27: Billance, Déclamé practice material 
The triplet figures occurring at rehearsal B were also something that needed to be practiced diligently. Using an eighth-note subdivision to practice this section isn't ideal as it would involve playing a polyrhythm. The way I practiced this section was by eliminating the ties across beats. I would practice it with a metronome to the quarter note, playing something that is shown in figure 28 . When I was comfortable playing this

A. Sax.

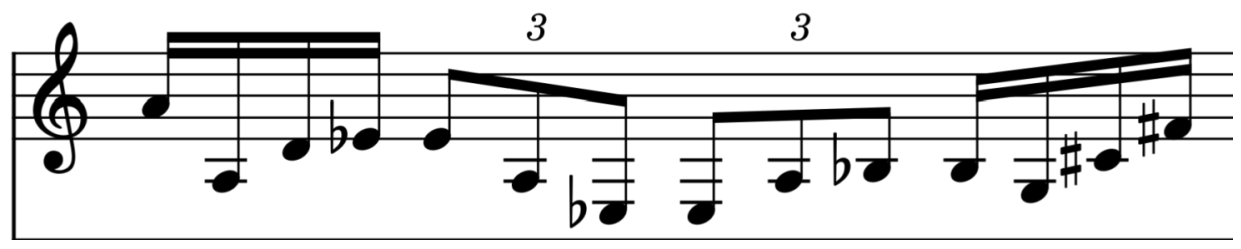

Figure 28: Déclamé Practice material

rhythm tongued I started including the ties. As I play this movement, this section at rehearsal $B$ is still the section that requires me to focus the most.

The final part of this movement that required the most practice were some of the tuplet runs, such as the one depicted in figure 29. To work on this line I was actually

A. Sax.

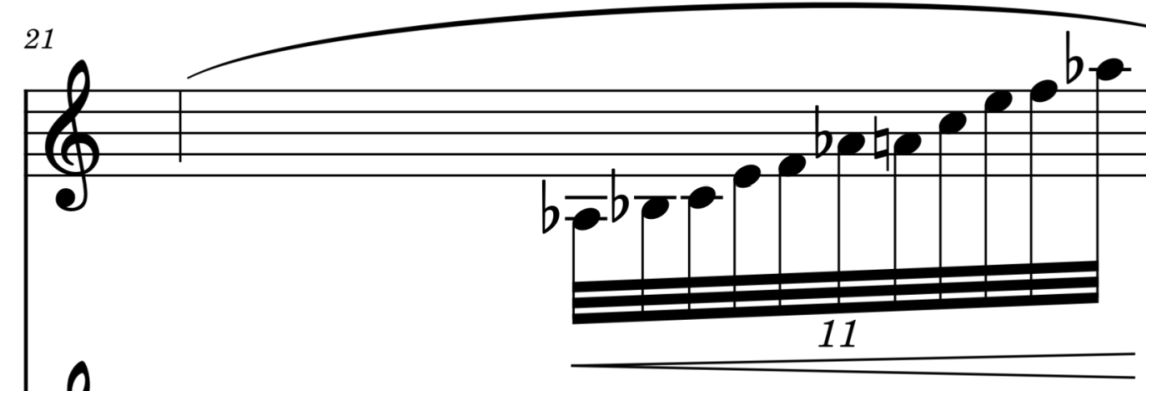

Figure 29: Brillance, Déclamé rehearsal C, m. 5

given advice by Dr. Erik Steighner, professor of saxophone at Pacific Lutheran University. His advice to work on this eleven-tuplet was to decide how I wanted to break it up. I settled on breaking it up into groups of five and six notes. I would practice each 
grouping individually with a metronome, a grouping to one beat. The tempo would gradually increase, and I would play them consecutively. Eventually when I had the quintuplet and sextuplet up to twice performance speed (96 bpm), I would drop the metronome to performance speed and play each tuplet under one beat, the notes evened themselves out and became an equal eleven-tuplet. The practice progression can be seen in figure 30 .

A. Sax.

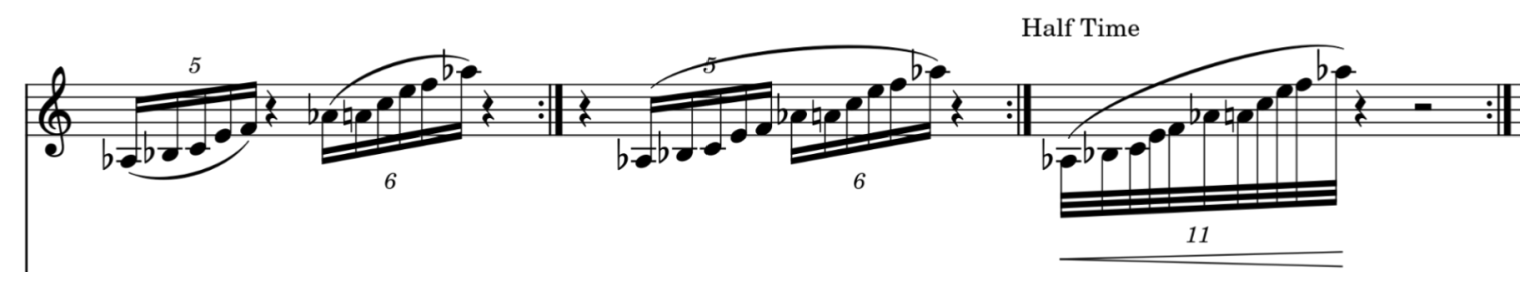

Figure 30: Déclamé practice material

\section{The Technique of Désinvolte}

Désinvolte is the first of the two technical movements. To play it, I focused my practicing efforts on the three main parts of the A sections. That being the straight eighth notes, the melodious chromatics, and the hemiola.

To play the eighth notes convincingly I had to be comfortable with the patterns and keep a strong continuous air stream. To be comfortable with the patterns I would practice something like this out of the Kynaston daily studies, see figure 31. To ensure my airstream was consistent I would practice setting my airstream first. I would begin by blowing a steady airstream using the desired amount of pressure and speed, and I would follow up with a couple of articulations making sure to place my tongue correctly 
and keep the air moving. Then without adjusting my air or tongue I would jump straight into the line I was practicing. This airstream practice was also how I practiced the next part of the A section, the chromatic melodious line.

A. Sax.

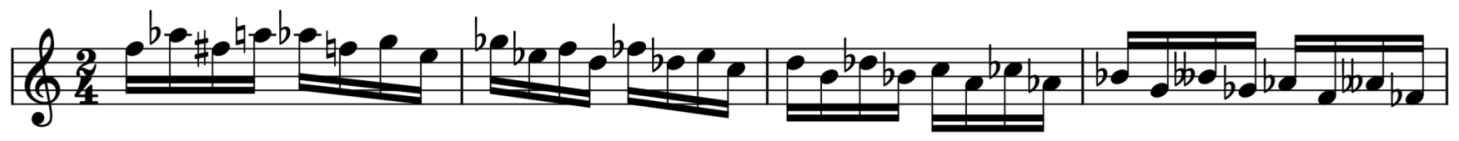

A. Sax.

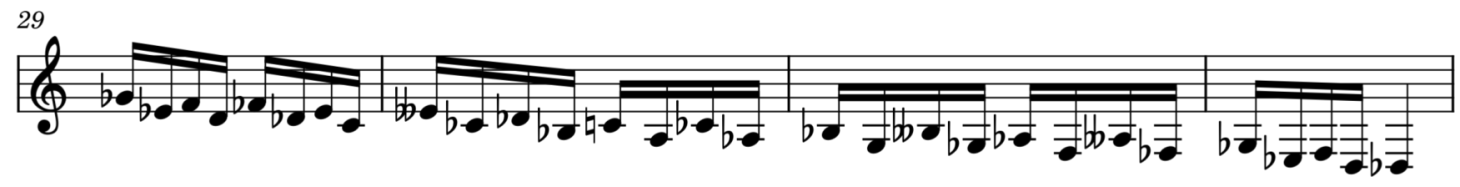

Figure 31: Kynaston exercise chromatic minor thirds

To effectively practice and perform the melodious line I had to play all of the octave/7th leaps as steadily as I could. This also took a good amount of air to keep things moving along. This practice of air in melodic sections served me well in working the $B$ sections as well. The soaring notes and denouement of the $B$ section require solid air to be convincing.

The last part of this movement that needed the most practice was the hemiola, pictured in figure 8 . I started practicing this by setting the metronome up very slow. I practiced it in two beat increments being sure to land on each of the correct beats. Slowly but surely I could increase the tempo and string together more and more beats until the whole string was learned. 


\section{The Technique of Dolcissimo}

Dolcissimo is the least technical movement of all. However that doesn't mean it's devoid of challenge. Its character as a beacon of sweetness requires a beautiful warm tone throughout the range of the saxophone. Practicing this melodious movement through its intricate harmony took a lot of practice to really nail down as well.

To work on my tone in this movement I did a lot of long tones on tonic and dominants, see figure 32 from the Kynaston book. This exercise really works to give a uniform tone across the range of the horn.
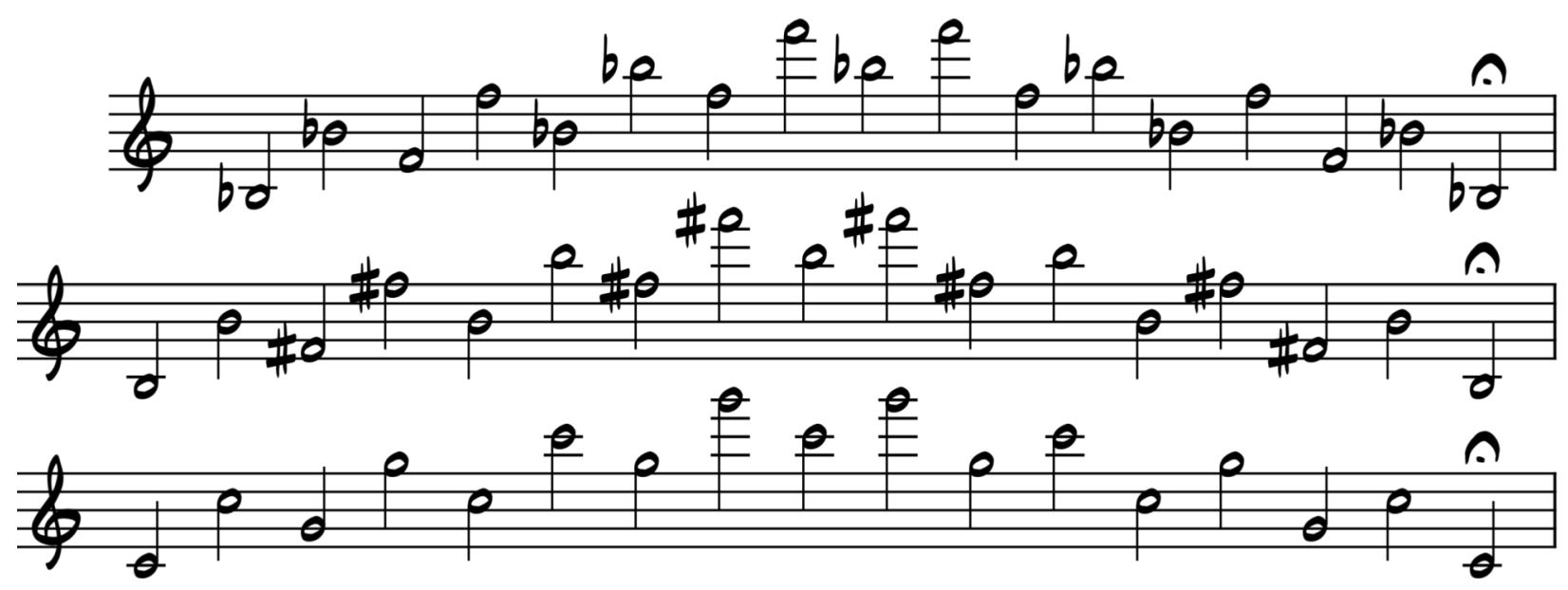

Figure 32: Kynaston exercise tonic and dominants

To practice being melodious through intricate harmony, the answer was twofold. Talk the piece slower than marked and sing the part. By slowing down and singing, I was able to take my time and hear the intervals between notes. Singing is an excellent tool on the belt of any musician. 


\section{The Technique of Final}

Final no doubt took me the most amount of time and effort to prepare. As a general rule of my practice, I focused on a high volume of slow reps. My goal was to work out these complicated runs as cleanly as possible at slow tempos before amping them up to speed. That goes for the exercises I used to prepare as well.

The very first thing that I practiced was measures 4-7, the augmented 7th run. Before I even began playing this I familiarized myself with the B-flat aug maj 7 chord, see figure 33. Just to play these 4 measures of music I dedicated at least an hour of total practice time just playing this chord repeatedly.

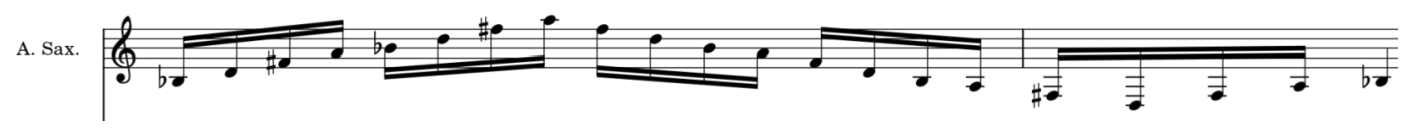

Figure 33: Final practice material

To play the alternating diminished chords at rehearsal B, I elected for direct practice of the part instead of an exercise. To learn these measures I used a technique that I would use quite a few times in preparation of this piece and many times in my overall practice. I would play the final beat, and just the final beat, to a metronome until it felt comfortable. I would then work in the beat before and play both beats. Once that felt comfortable, I would again work in the prior beat. This process continues until a line is learned. Only once a line was learned could start speeding it up.

Rehearsal C involved hovering around a specific pitch, with brief jumps up. This kind of movement takes a lot of fast air to allow every note to speak. To practice this I would play the lines with added crescendos so that I could be sure I was pushing my air 
at an appropriate speed. As I got closer to my performance tempo I would ease off crescendos and allow the air stream to be fast but steady.

For the first time change section I had to ensure that my agogic stresses were convincing, while keeping accents off of the off beats. I fell into a habit of accenting every note instead of just the stressed beats. To walk this habit back, the answer was to actually slow this section down. In practice, I would bring this section down in tempo to give myself more time to think about my air and accents. I eventually brought the tempo back up with the newly formed correct habit, and all in all it only took me two practice sessions to fix it.

Rehearsal $\mathrm{H}$ was quite a fun line to play. I call it transitional material in my analysis but it is still complex and intriguing material that features time changes and compound interval leaps. To play this section through the time changes I actually learned it under a different beat pattern. Instead of playing it as written, I practiced the first note as if it were upbeat, and the second note is the downbeat. Playing it this way meant I didn't actually have to worry about the time changes and can actually feel it as straight. Once I had learned the line, I worked on putting it back into context. See figure 34 for how it's originally written and figure 35 for how I felt it in practice.

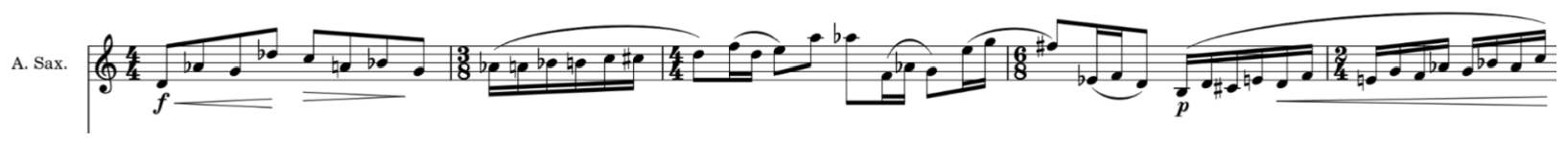

Figure 34: Brillance, Final rehearsal $H, m m .3-7$ 


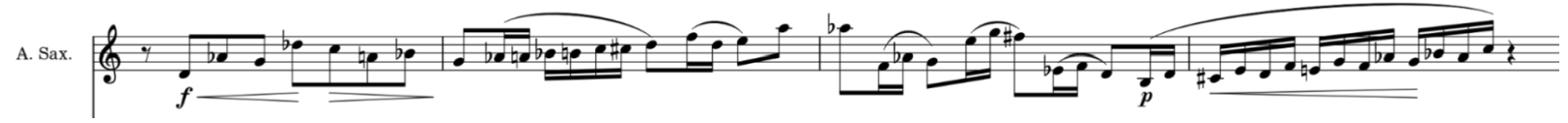

Figure 35: Final practice material

The augmented chord flourishes at rehearsal letter I were shockingly difficult to get under my fingers, even at slow tempos. I played exercises like the one shown in figure 36 to prepare. The first two flourishes are the same base chord, however the second has an added F-sharp. I put a lot of work into getting my hands accustomed to the first 7th chord, adding this sharp-ninth felt really foriegn.

A. Sax.

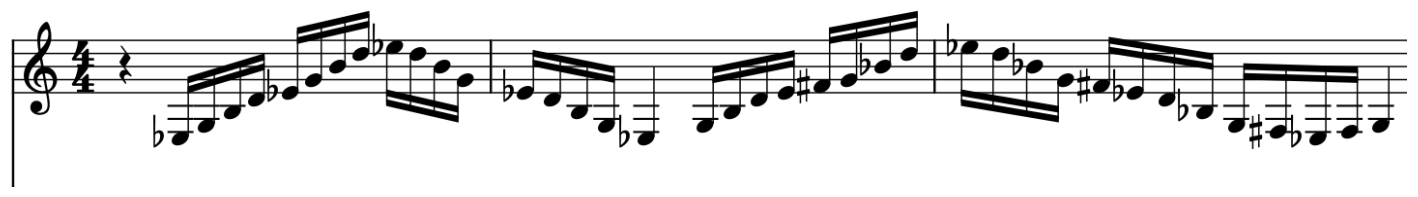

Figure 36: Brilance, Final practice material

The final stretch of the movement really just took me rep after rep. To start I took it really slow and grouped measures by chord changes. Eventually I would string these changes together until I could play the full stretch without stopping. A struggle that l've had with this finale is my endurance at playing such repetitive lines. It takes real effort for me to be present in the moment and prepared for what comes next.

What came next was the bombastic finale. The finale itself wasn't challenging, but where I really needed work was the transition from the time change section to the finale section. As stated before, I struggled with staying present in the repetitive lines and when it would move to the new section, I would be almost caught off guard and freeze. To practice this transition, I would play the last measure of the repetitive section 
and the first measure of the finale back to back over and over again. My goal was to form a habit out of this transition. If the habit was formed and I did lose myself in the moment, the habit would catch and I wouldn't surprise myself. I would then have the time to reorient myself on the following half note and end the piece strong. 


\section{Rehearse}

\section{Piano Tracks}

In the time of the COVID-19 pandemic, in-person performance and rehearsal is severely limited. Instead of numerous live rehearsals, my accompanist and I were limited to a single meet in person. A meeting where, per university guidelines, I was not allowed to play my instrument. This puts a whole new dynamic on preparing music with an accompanist.

My accompanist, Dr. Chuck Dillard, and I only had one hour to record piano tracks for the performance. This severely expedited the process. We decided to move chronologically through each movement. To ensure that his performance and my performance tied together, I stood before him, saxophone in hand, gesticulating and singing my part aloud. When we felt prepared with a movement it was time to record, which of course could only be done through cueing.

Déclamé took the clearest cueing and gesticulation to perfect. The piano's long held chords meant I had to audiate my performance as accurately as possible so that it all lined up. Once I had the piano track there were certain moments where I had to add a click track to cue myself. This proved to be mostly successful.

Désinvolte was much more clearly rhythmic. In rehearsal of this movement I resorted to more conducting than motioning. Keeping a steady beat through conducting was important but there were numerous times in both the rehearsal and recording of this movement that I just trusted Dr. Dillard to play his part well. The beginning took a click track to ensure a simultaneous start, but once the music really started going, 
around rehearsal A, a click track was no longer necessary.

Dolcissimo was the quickest movement to put together. Despite its more subtle time changes we were able to rehearse and record purely through cueing. The part that I had to ensure was the clearest was the ad lib. section after rehearsal B. I had to be sure to audiate my part as close to my interpretation as possible. An inaccuracy between the piano track and my interpretation would mean having to alter my practiced interpretation on the fly.

Final was the only movement that had to be recorded in two part chunks. The first recording ended at the cadenza, and the second picked up just after. In this second section. The beginning of this movement is incredibly rhythmic, I just had to maintain a steady beat and Dr. Dillard could just play along. The second half required a little more input on both our parts. I did my best to lead through the mixed meter sections of rehearsal $\mathrm{F}$ and just let Dr. Dillard play his straight 8th notes at rehearsal $\mathrm{H}$ without me leading him at all.

\section{Solo Rehearsing}

Solo rehearsing is a very strange concept. As rehearsal is something typically done between two or more musicians, so to design a rehearsal with one person and piano tracks feels very foriegn. I achieved this by setting attainable goals and standards for myself in these solo rehearsal sessions.

The primary rule that I gave myself to follow was that rehearsal time is not practice time. This is a rule that can be found in many orchestra and band rehearsals at 
the collegiate level. Rehearsal is a time to line things up, not work out technique. So if I ran into a line where my technique wasn't up to speed, that was not the time for me to bring out the metronome and work the line. This happened specifically in Final at rehearsal $\mathrm{H}$, figure 34. I wasn't able to effectively play the line in my initial rehearsals, so I simply noted that and practiced it later on.

My goals for rehearsal were to make recording go as smoothly as possibly. This meant familiarizing myself with the piano tapes and how they fit in context with the saxophone part. I filled my part with piano cues and notes of where the click track was. I wrote time stamps on my sheet music so I could jump to specific parts in the tapes to rehearse more effectively. I would run down entire movements and sections to ensure that I could lock into the piano track.

While solo rehearsal felt like an enhanced practice session, I was able to work on things I wouldn't have otherwise been able to. Such as playing in tune to a piano. I would rehearse with a speaker playing the piano tracks, or an earbud playing in my ear. These two forms that my rehearsal took felt very different. While playing with the piano tracks out loud felt the most comfortable, it wasn't practical for me to record myself. I had to get used to playing with an earbud. Tuning becomes very difficult when soundwaves aren't resonating with each other, and it is made even more difficult when I'm only hearing myself with one ear.

These hurdles had to be overcome by both rehearsal and practice. So while the rehearsal stage was upon me, I never left the practice stage. However with enough work, I eventually felt ready to record my final product. 


\section{Perform}

The performance of this piece looked very different from what a typical performance of any music would look like. This performance took place in my bedroom with a laptop camera and a USB microphone. Suddenly a convincing performance became more than knowing the music well and being well rehearsed, it became about how I set up the lighting and where I put the microphone.

It felt very limiting to be working in such a small space. Instead of projecting my sound and playing to the back of the room as I would in a recital hall, I had to keep one eye on the light of my microphone to ensure I wasn't peaking. All the while, I was discouraged because I knew that a certain amount of nuance was going to be lost because of my less-than-professional recording set up.

In many ways, recording is harder than live performance because of how easy it is to get caught up with mistakes. In a live play, a musician has to have a short memory, the mistakes have to be forgotten as they happen because there is more music to play. However in a recording, it is way too easy to just stop the recording and restart. Which I did many times.

To somewhat combat the constant restarting, I decided to do all of my playing in single takes. Meaning one video recording may contain three to four rundowns of a movement. If I made a mistake in one of those rundowns I willed myself to push through it and finish the take. In the end, all of my final videos are ones that I contemplated stopping on.

I had no flawless takes of any movement. Every movement has multiple mistakes 
that are glaringly obvious to me. I am not proud of my final product. There are many things that I wish I could go back and fix. Despite this piece making up less than a quarter of my senior recital, my perceived failure of it hangs heavy over my head. As a musician and as an artist, a failed product can feel almost disqualifying of the 50 some odd hours of work that proceed it.

However, I have elected to refuse this notion. I have dedicated more time in my life to practicing in this last term than I ever have before. I learned a tremendous amount while preparing Brillance, and have gained skills through it that will carry on to my next performance of it. My own knowledge of how I prepare music has been enhanced by it. I feel better equipped and even motivated to prepare even harder music.

So while a poor final performance is disappointing, a 11 minute recording cannot redefine 50 hours of gruelling unwavering dedication. 


\section{Bibliography}

Chien, William. "Ida Gotkovsky- Brilliance." William Chien. 2017. Youtube. https://youtu.be/OYSxX-q5Gcl

Gotkovsky, Ida. Brilliance pour saxophone alto et piano. France: Gérard Billaudot Éditeur, 1974.

Gotkovsky, Ida. Catalogue, 2017.

http://www.gotkovsky.com/textes_versionFR/txt_fiches_des_oeuvres/ff_quat.htm

Glen Spring and Jere Hutcheson. Musical Form and Analysis. Waveland Press, inc.

(Long Grove, IL), 1995.

Nascilansky Duo. "BRILLIANCE. Ida Gotkovsky." Nascilansky Duo. June 1, 2018.

Youtube video, 9:49. https://youtu.be/EHWFutRwO8k.

Persichetti, Vincent. Twentieth Century Harmony, Creative aspects and Practice. Norton \& Company, 4th edition, 1961.

Speath, Merrie. Practicing Vs. Rehearsing A Presentation: What's the Difference and Why You Should Care. Forbes, 2020.

Stravinsky, Igor. "The Performance of Music,"in Poetics of music in the form of six lessons, edited by Vintage Books. Alfred A. Knopf INC, Harvard University Press, 1947.

Surman, Patricia. "Gotkovsky, Ida." Grove Music Online. October 29, 2020. Oxford University Press.

https://www-oxfordmusiconline-com.proxy.lib.pdx.edu/grovemusic/view/10.1093/ gmo/9781561592630.001.0001/omo-9781561592630-e-90000341874 